\title{
"DIPLOMACIA TOTAL": MULTIGEOPOLITICIDAD, GRANDEZA DE MÉXICO*
}

\section{José Juan de OLLOQUI**}

RESUMEN: La política exterior mexicana, tradicionalmente orientada por los principios incorporados en nuestra Constitución, puede replantearse empleando las ventajas geográficas mencionadas para impulsar una posición de liderazgo internacional. Tal política permitirá además tomar ventaja de las características del país como hispanohablante, como potencia cultural y economía emergente. Todo esto conduce a la práctica de lo que el autor denomina "Diplomacia total", que implica aprovechar todas las oportunidades y flexibilizar las relaciones exteriores. Este tipo de relación con el exterior requerirá de la identificación del interés nacional, de la realidad internacional y de que se evalúen los recursos disponibles.

ABSTRACT: Mexican foreign policy, traditionally oriented by the principles incorporated in the Constitution, can be redesigned using these geographical advantages, to encourage a leadership role in the international arena. Such a policy will enable Mexico to benefit from its characteristics as a Spanish speaking country, as a cultural power and as an emerging economy. All this leads to the adoption of what the author calls "Total Diplomacy" that consists of using all the available opportunities and to make foreign foreign policy more flexible. This type of foreign relations will require that national interest, international reality and available resources are clearly identified.

RESUMÉ: La politique extérieure mexicaine, traditionnellement orientée vers les principes incorporés dans nôtre Constitution politique permet cette réorientation en utilisant ces avantages géographiques pour impulser une position de leader international. De plus, cette politique permettra de tirer avantages des caractéristiques du pays en tant que pays hispanophone et comme une puissance culturelle et économique émergeante. Tout ceci conduit à la pratique de ce que l'auteur appelle "Diplomatie Totale", laquelle implique l'utilisation de toutes ces opportunités et flexibilise les relations extérieures. Ce type de relations nécessite l'identification de l'intérêt national, de la réalité internationale et de l'évaluation des ressources disponibles.

* Este artículo sucede a la ponencia del mismo nombre, leída por el autor en la Universidad Iberoamericana el 25 de enero del 2000, en la ciudad de México.

** Investigador del Instituto de Investigaciones Jurídicas de la UNAM. 
SUMARIO: I. Marco jurídico y reflexiones teóricas. II. Implicaciones geopolíticas en México. III. El Tratado de Libre Comercio con América del Norte. IV. Las condiciones de negociación para México. V. El nuevo mapa de Norteamérica. VI. La búsqueda de un puente con Europa. VII. La conjunción de Norteamérica con América Latina. VIII. La opción: política de abanico.

IX. Conclusión de la "Diplomacia total".

Se ha dicho que en términos de política internacional el siglo XX fue muy corto pero intenso. Comenzó con la Primera Guerra Mundial y terminó con el fin de la Guerra Fría, la caída de la Unión Soviética y el desmembramiento del bloque socialista. Así como al final de la Primera Guerra Mundial se establecieron los arreglos internacionales que acabarían por desembocar en conflictos posteriores que aún siguen latentes, durante los últimos años de la década pasada se crearon las condiciones que determinarían las relaciones internacionales en los años por venir.

Podemos pensar que actualmente, la apertura comercial que, salvo en contadas excepciones, se da prácticamente en todas partes del globo, es lo que caracteriza en buena medida la relación entre los países.

Quizá es posible afirmar que ya estamos viviendo en un mundo que tiene las características de lo que habrá de ser la primera parte de este nuevo siglo, y que podrían apoyarse en cinco pilares básicos:

1. Primacía de los asuntos económicos sobre los temas tradicionales de seguridad militar. Nunca desaparecerá la preocupación por la seguridad nacional; seguirán los conflictos, pero será más limitada su extensión y duración. Es posible aseverar, por ejemplo, que durante la Guerra Fría los problemas de Irak o los Balcanes hubieran tenido otras proporciones. ${ }^{1}$ Aunque en última instancia, la seguridad nacional será determinante.

2. Multipolaridad del sistema internacional, cuyos centros de poder económico y político serán América del Norte, la Unión Europea, Japón y eventualmente China. En la actualidad nos encontramos en un mundo unipolar $^{2}$ en lo militar y tripolar $^{3}$ en lo económico.

1 El caso de Irak en 1991 ilustra la magnitud y la dinámica de las guerras de fin de siglo. En la "Tormenta del Desierto" se utilizó la última tecnología militar, pero era muy claro que el móvil era de carácter económico y se guiaba por los intereses de Estados Unidos de América y las potencias de Occidente en el mercado del petróleo.

2 Encabezado por Estados Unidos de América.

3 Eventualmente definido como la triada. 
3. Enfrentamiento de los polos de poder por problemas de carácter económico que, si no se resuelven, podrán desembocar en tensiones políticas más graves de las existentes entre los principales actores económicos. Las tensiones entre Japón, Europa Occidental y Estados Unidos de América, aliados durante la Guerra Fría, comenzaron desde la década pasada por el creciente proteccionismo japonés y el déficit comercial de Estados Unidos de América. Por otra parte, el proceso de formación de bloques tiene un efecto contradictorio, ya que si bien se les ve como un paso intermedio para el libre comercio mundial, también se les mira con recelo ante la posibilidad de que se levanten barreras proteccionistas.

4. Sistemas de alianzas económicas construidas alrededor de los bloques comerciales. La importancia de las alianzas militares que construyeron las dos superpotencias está disminuyendo por la aparición de alianzas económicas dentro de los bloques. Algunos países del llamado Tercer Mundo que no se encuentran cerca de los polos de poder económico y están buscando alianzas con sus vecinos para no marginarse de esta corriente internacional. Tal es el caso, por ejemplo, del Mercosur o la formación de asociaciones económicas en el Pacífico. ${ }^{4}$

5. Globalización ${ }^{5}$ de algunos temas de la agenda internacional. Replanteamiento de la situación de los derechos humanos, la democracia y la ecología, así como el renacimiento de problemas que parecerían haber desaparecido por los imperativos de la Guerra Fría, como la xenofobia, el racismo, la migración hacia los centros de poder económico y las tensiones interétnicas.

\section{MARCO JURÍDICO Y REFLEXIONES TEÓRICAS}

Para entender el ámbito jurídico en el que se tratan los temas nacionales e internacionales, consideramos necesario exponer algunos de los

4 México está particularmente favorecido por su multigeopoliticidad (término que explicaremos más adelante), o como lo están también en menor medida los países de Europa del Este (por la vecindad con los antiguos miembros de la Unión Europea y Alemania en particular). Ventaja que no disfrutan los países que pertenecen al Mercosur, ya que Brasil no puede recibir ni impulsar el desarrollo que da la vecindad de países como Estados Unidos de América, Alemania y Francia. En Asia falta todavía un largo trecho por recorrer para establecer mecanismos de libre comercio como los que mencionamos.

5 Véase definición de globalización en el punto VII de la ponencia de Olloqui, José Juan de, "Identidad, globalización y relación de México con Estados Unidos", X Congreso de la Asociación Mexicana de Estudios Internacionales, Identidad y Globalización, Oaxtepec, México, 28-30 de noviembre de 1996. 
principios básicos del derecho internacional. Como bien lo enunció César Sepúlveda, ${ }^{6}$ el derecho internacional es conocido también como derecho de gentes, y cubre un ámbito que, si bien es amplio, puede ser demasiado general e impreciso para denotar las relaciones entre Estados y no incurrir en el ámbito privado. Es por lo anterior que aquí hablaremos principalmente del derecho internacional público e indicaremos cómo convive éste con la política internacional, que por su naturaleza no siempre está sujeta a normas de derecho.

Las funciones del derecho internacional comprenden, entre otras cosas, la creación de un marco jurídico para la convivencia de los Estados, la reglamentación de las instituciones de carácter internacional y de los demás actores internacionales. Así pues, al enunciar al derecho internacional nos referiremos también, la definición descrita por César Sepúlveda, en donde el derecho internacional público puede definirse como el conjunto de normas jurídicas que regulan las relaciones de los Estados entre sí, o más correctamente, el derecho de gentes que rige las relaciones entre los sujetos o personas de la comunidad internacional. ${ }^{7}$

México está sujeto al marco jurídico internacional e interactúa con Estados con legislaciones propias. Asimismo, cabe destacar que en el interior del país, nuestras fuentes de derecho internacional tienen diferente grado de uso y aceptación. Si bien los tratados son considerados ocasionalmente como una fuente limitada de derecho, el contexto internacional ha hecho que México les de particular importancia recientemente; los tratados internacionales han obtenido relevancia en el ámbito comercial y México ha observado con especial interés al Tratado de Libre Comercio con América del Norte y el Acuerdo de Libre Comercio con la Unión Europea, como su consecuente. Un tratado es el consenso entre dos o más partes en la transmisión de derechos o beneficios con la adquisición de obligaciones mutuas. ${ }^{8}$ No obstante que un acuerdo no tiene la formalidad jurídica de un tratado ni su grado de compromiso, es el mejor precedente para incrementar lazos de cooperación y crear intereses mutuos. ${ }^{9}$

México ha seguido tradicionalmente durante el siglo XX los principios de política exterior establecidos en la Constitución de 1917. Por razones consideradas por algunos de interés nacional, las fuentes del dere-

6 Antiguo profesor de la UNAM y diplomático mexicano.

7 Sepúlveda, César, Derecho internacional, México, Porrúa, 1997, p. 3.

8 Véase Blaks Law Dictionary, West Publishing Co., St. Paul MN., 1991.

9 Véase Buergenthal, Thomas et al., Manual de derecho internacional público, México, FCE, 1994. 
cho internacional como la costumbre, los principios generales de derecho, la jurisprudencia, la doctrina y la codificación del derecho se han estudiado y proyectado con base en nuestros principios de política exterior. Nuestras posturas en los organismos internacionales se han caracterizado por esta contundencia.

Los principios de política exterior de México están contemplados en su Constitución política, lo cual los hace legales, pero no necesariamente los únicos en el mundo ni adecuados a los tiempos políticos. Según la opinión de los teóricos realistas, los países débiles o sensibles tienden a promover políticas de principios para asegurar su autonomía y supervivencia. Si bien México ha accedido con el TLCAN al bloque comercial más importante del mundo, no está por demás revisar su posición mundial de poder y la utilidad que le han dado sus principios de política exterior que son "la autodeterminación de los pueblos; la no intervención; la solución pacífica de las controversias; la proscripción de la amenaza o el uso de la fuerza en las relaciones internacionales; la igualdad jurídica de los Estados; la cooperación internacional para el desarrollo; y la lucha por la paz y las seguridades internacionales". ${ }^{10}$

Un hecho particular del siglo XXI es que las políticas exteriores están siguiendo a las políticas económicas. Esto tiene como consecuencia el aumento de la importancia de los organismos económicos internacionales y del derecho internacional privado. Es conveniente para México conocer y manejar las normas destinadas a la resolución de los tribunales de los diferentes Estados, de los conflictos de leyes derivados de la multiplicidad de los sistemas jurídicos. ${ }^{11}$ Ahora más que nunca, las legislaciones militares y de seguridad se supeditan al ámbito comercial. Hemos pasado, como bien diría el diplomático inglés Harold Nicholson, de la diplomacia del guerrero a la del tendero. ${ }^{12}$

\section{IMPLICACIONES GEOPOLÍTICAS EN MÉXICO}

México tuvo que enfrentar desde su nacimiento amenazas a su soberanía e integridad, y nuestra actitud se reflejaba en una forma defensiva. ${ }^{13}$

10 Constitución Politica de los Estados Unidos Mexicanos, México, ISEF, artículo 89, título tercero, capítulo III, párrafo X, 1999, p. 47.

11 Véase Pina, Rafael de, Diccionario de derecho, México, Porrúa, 1996, p. 235.

12 Véase Nicholson, Harold, La diplomacia, México, FCE, 1975.

13 Véase González Aguayo, Leopoldo, "La geopolítica y el poder nacional", Relaciones Internacionales, México, núm. 61, enero-marzo de 1994, p. 75. 
Por otra parte, siempre hemos fracasado en buena medida en lo relativo a diversificación de nuestras relaciones; aunque ya la hemos logrado en cuanto a productos se refiere, no así al destinatario de éstos, que sigue siendo Estados Unidos de América. ${ }^{14}$ Por la vecindad geográfica con la primera potencia mundial y sus implicaciones, hemos buscado tradicionalmente independencia y diversificación, aunque sin mucho éxito. Es bien sabido que un país no puede ejercitar todas sus opciones políticas y económicas si depende de un solo mercado o de un solo producto. ${ }^{15}$

Durante la década de los años sesenta y setenta, en alguna medida intentamos cambiar las reglas del juego económico y comercial para propiciar una mayor participación en el comercio y las finanzas. También en la década de los sesenta tratamos de impulsar una integración con América Latina con más optimismo que resultados. Así, en general, continuamos con una política sustitutiva de importaciones, proteccionista por definición, que pensábamos nos permitiría, con el fortalecimiento de la industria nacional, competir con ventajas en el ámbito internacional.

El modelo se agotó y a principios del 82 nos encontramos con una industria muy deficiente, un Estado que gastaba acciones y recursos en proteger esta industria a través de subsidios directos e indirectos, un endeudamiento exterior excesivo y una enorme dependencia del petróleo, que, para colmo, bajó de precio. ${ }^{16}$ Ante ese panorama se inició nuestro proyecto de apertura económica y desregulación estatal.

Considerando las limitaciones de nuestro mercado interno y las tendencias mundiales a los bloques comerciales, la solución para México está en volcarse hacia el exterior. En particular, porque está ubicado junto al enorme mercado que es Estados Unidos de América, y porque goza de una extraordinaria multigeopoliticidad, derivada de su singular ubicación geográfica. ${ }^{17}$ Esto en buena medida debe ser la base de nuestro proyecto como

14 Véase Saxe Fernández, John, Nafta: los cruces de la geopolítica y la geoeconomía de capital, México, UNAM, 1994, pp. 7-37.

15 Hay pocos mexicanos que le den prioridad al tema de la seguridad nacional, como lo hacen sus contrapartes estadunidenses. Clark W. Reynolds y Stephen J. Wayer no sólo revelan los temas de seguridad como escasos y visionarios, sino como fundamentales para México, aunque se les estudie más en Estados Unidos de América que en este país. Véase la paráfrasis de los autores que se hace del planteamiento de José Juan de Olloqui, en Aguayo, Sergio (comp.), "Integración económica de México y Estados Unidos. Implicaciones para la seguridad de ambos países”, En busca de la seguridad perdida, México, Siglo XXI, 1990, p. 216.

16 Véase la crisis petrolera iniciada en 1973 y sus repercusiones negativas en México a principios de los ochenta.

17 Véase Olloqui, José Juan de, La diplomacia total, México, FCE, 1994. 
nación, si queremos llegar a la grandeza, a la que en nuestra opinión estamos condenados, y de la cual nos ocuparemos al final de este texto.

\section{EL TRATADO DE LIBRE COMERCIO CON AMÉRICA DEL NORTE}

A principios de la década de los noventa, México se dio cuenta de que Europa estaba demasiado interesada en sus propios problemas y que Japón no sentía que fuera el momento de involucrarse decisivamente con México. Por otro lado, los tiempos políticos de Asia no coinciden con los nuestros, y a sus países difícilmente les interesan nuestros procesos políticos.

Analizando la situación actual, repasemos algunos antecedentes que nos den mayores elementos de juicio. Respecto al Tratado de Libre Comercio con Estados Unidos de América y Canadá, la pregunta que estaba en el aire era si un arreglo de esta naturaleza nos haría más o menos soberanos, más o menos dependientes de Estados Unidos de América. Podemos basar estas legítimas preocupaciones a la luz de las siguientes consideraciones:

- El intercambio económico entre Estados Unidos de América y México estaba ya tan interrelacionado, que con o sin tratado seguiríamos concentrando una buena parte de nuestras relaciones económicas con el país vecino.

- No sólo el intercambio económico es ineludible, sino que la vecindad geográfica es un hecho inamovible y sería absurdo que siendo vecinos de uno de los mercados más grandes del mundo le diéramos la espalda.

- Un Tratado de Libre Comercio no significa, por más adecuaciones internas que exija, que se ate la política exterior de un país respecto de aquél con quien se ha firmado. Es preciso estudiar el caso de $\mathrm{Ca}$ nadá que, aunque tiene intereses convergentes con Estados Unidos de América, conserva un espacio de maniobra en función de su riqueza. Aquí baste decir que, por más intenso que sea el intercambio entre México y Estados Unidos de América, somos un país fundamentalmente distinto que percibe su lugar en el mundo de una manera peculiar y que tiene múltiples dimensiones cuya política exterior debe atender. 
La sola idea de que pudiera firmarse un tratado de libre comercio entre México, Estados Unidos de América y Canadá motivó a la vez gran inquietud y expectativas entre los mexicanos. Quienes veían en esta posibilidad un cambio sustancial en su modo de vida. Estados Unidos de América siempre ha sido para los mexicanos un irritante insuperable, por ser el causante de la pérdida de más de la mitad del territorio, así como el responsable de numerosas intervenciones y presiones. Si bien, por otra parte, también ha generado una rencorosa admiración por sus logros y el deseo de culparlo de nuestros problemas cotidianos. A pesar de todo esto y con múltiples justificaciones, no podemos dejar de tener un sentido de elegante superioridad en nuestros valores culturales.

\section{LAS CONDICIONES DE NEGOCIACIÓN PARA MÉXICO}

En una época de integraciones globales, un tratado de libre comercio era quizá para México la solución que le permitiría llegar a una etapa de mayor bienestar. Así surgió la pregunta: “¿En qué afectó la firma del Tratado de Libre Comercio de América del Norte (TLCAN) a nuestra relación con el mundo?"; y la respuesta sería: "No tanto como podría pensarse". ${ }^{18}$

Respecto de Estados Unidos de América, en lo económico, lo que hizo realmente el tratado fue dar una estructura institucional a lo que ya de hecho existía de manera parcial. Particularmente se regularon ciertas regiones y sectores, tales como la frontera norte y la industria automotriz. Se instrumentó un acuerdo que serviría para reconocer las diferencias entre los niveles de desarrollo de las tres naciones, y que sería un mecanismo adecuado para la discusión y solución de disputas. ${ }^{19}$

El tratado ha agudizado nuestra preocupación —más discursiva que de hecho- en relación con los conceptos de soberanía e independencia nacionales. Aunque las cifras son aburridas, también son indispensables para apreciar algunos resultados. En 1984 nuestras exportaciones eran mayormente petroleras, y en menor grado agropecuarias y extractivas. Actualmente, son en su mayoría de manufacturas, según lo indica la cuenta corriente del 2000 analizada por el Banco de México. Por otro lado, del total mundial de exportaciones de $152,857.74$ m. d., en la eva-

18 Véase Tratado de Libre Comercio de América del Norte, México, Ediciones Guernica, 1994.

19 Véase el caso del sector agrícola en Calva, José Luis, Probables efectos de un Tratado de Libre Comercio en el campo mexicano, México, Fontamara, 1994. 
luación del año 2000, 135,616.18 m. d. (88\%) fueron destinados a Estados Unidos de América, lo que muestra una clara dependencia en nuestro comercio exterior. ${ }^{20}$

El tratado ha permitido que México compense sus desventajas como exportador tardío ante la fuerte competencia de otros países, principalmente de Asia, al grado que hemos quintuplicado nuestra exportación y somos la décima potencia comercial mundial y la primera de América Latina. Según datos de Secofi $^{21}$ y el Banco de México, ${ }^{22}$ con el TLCAN las exportaciones anuales promedio de 1991 a 1999 de México a Estados Unidos de América se incrementaron $19 \%$, mientras que las del resto del mundo sólo 9\%, al grado que les exportamos más que China y Singapur, que Alemania y el Reino Unido, y por supuesto que el resto de América Latina.

Obviamente, el sector exportador es el principal generador de empleos, que pagan mejor que el resto de las otras actividades económicas. Nos guste o no, las empresas maquiladoras ${ }^{23}$ pagan salarios cuatro veces mayores al salario mínimo en México. Podríamos decir que por ahora el TLCAN es un éxito, sin embargo, la negociación pudo ser mejor si se hubieran atendido las tres piedras angulares de toda la negociación: selectividad, gradualismo y reciprocidad. Consideraciones que no fueron cabalmente atendidas, aunque el esquema fue atinado en su momento histórico. Veamos lo anterior:

- Reciprocidad. Si abrimos nuestro país a la inversión y a los productos del exterior, debemos pedir a cambio que nuestras empresas y capitales puedan operar bajo las mismas condiciones en el extranjero. Tal reciprocidad debe tomar en cuenta, además de nuestro grado de desarrollo. Debemos y podemos obtener concesiones especiales de los países que estén mejores dotados para competir en nuestro mercado, condición que se denomina como: reciprocidad relativa.

- Selectividad. No es necesario ni quizá conveniente abrir nuestra economía de manera irrestricta. En primer lugar debemos establecer los ámbitos donde nos abriremos a la presencia extranjera, de acuer-

20 Véase tablas de comercio exterior por zonas geoeconómicas en "México en cifras" en la página electrónica del Banco de Comercio Exterior: www.bancomext.com.

21 Ahora Secretaría de Economía, revisar el boletín de prensa núm. 11 del 22 de enero del 2001 de esta dependencia.

22 Véase indicadores económicos en: www.banxico.org.mx.

23 Nombre corriente para la industria manufacturera y en donde la plusvalía se deriva de la mano de obra barata. 
do con nuestros intereses, así como los países o bloques de países con quienes nos conviene estrechar vínculos económicos.

- Gradualismo. No tenemos por qué abrir nuestra economía de un día para otro. Podemos establecer distintos plazos en diferentes sectores para permitir que la economía nacional sea capaz de ajustarse a las exigencias de un mercado más competido.

Las empresas mexicanas tendrán que hacer un gran esfuerzo para alcanzar mayores éxitos en el mercado de América del Norte bajo las nuevas reglas de calidad y competencia. Sería muy valioso para México que lograran realizarse las transformaciones cualitativas y de producción que ello requiere, pues se generaría un alto grado de competitividad. Aquí se encuentra la oportunidad de reestructurar nuestra economía a fondo, desechando lo que ya hemos comprobado que no nos sirve, y adaptando o innovando nuestro propio modelo de desarrollo, un "modelo mexicano", ya que lo que es bueno para un país de dimensión y población reducidas y de distinta ubicación geográfica, como el caso de Chile, no es necesariamente también bueno para nosotros. En el pasado no solíamos copiar modelos ajenos; teníamos un eficaz modelo mexicano que, si bien se agotó en algunos aspectos, pudo ser adaptado a nuestras actuales circunstancias.

Si bien, el tratado hasta ahora ha sido un instrumento positivo para México, no ha sido posible evitar que afecte negativamente algunas actividades. Ha existido prepotencia para resolver algunos problemas, como por ejemplo, el acceso de camiones de transporte a Estados Unidos de América. En donde se alegó, entre otras cosas, el mal estado de nuestros vehículos.

\section{EL NUEVO MAPA DE NORTEAMÉRICA}

El fenómeno del tratado, más allá de lo económico, saca a la luz nuestra identidad como mexicanos, que en opinión del autor, nunca vamos a perder. Lo que podríamos llamar "tres méxicos" (el norte, centro y el sur) está integrado por áreas con características propias; la ciudad de México y su zona metropolitana virtualmente suele estudiarse por separado. El norte es el más dinámico y próspero, por lo tanto es el más susceptible de recibir la influencia de Estados Unidos de América y, lógicamente, también de tener incidencia en las otras zonas de México.

Nuestra preocupación por la frontera, entendida ésta no sólo como la línea que nos divide, sino como un espacio que se va agrandando y ate- 
nuando a medida que se aleja de la línea divisoria, es exagerada. Asimismo, durante varias generaciones, nuestros fronterizos han estado acostumbrados a una relación fluida con Estados Unidos de América. Paradójicamente, lejos de que esto se haya acentuado en el lado mexicano, ha ocurrido lo contrario, pues se está conformando una zona cultural muy particular en el lado estadounidense. Así, por ejemplo, se habla más español que inglés en Laredo, Brownsville o el Paso, Texas. Cabe decir que hace cincuenta años esto no era así; ahora se escucha música mexicana, o una versión de ésta; y la mayoría de la población es de origen mexicano. Como es obvio, el fenómeno se va diluyendo en la medida en que nos alejamos de la frontera propiamente dicha.

México es distinto y numeroso como para temer la erradicación de su propia identidad. Quiere progresar, pero sin dejar de ser él mismo. Vale la pena anotar que, aunque se modifiquen las pautas de la relación entre México y Estados Unidos de América, ésta es y seguirá siendo por mucho tiempo extraordinariamente asimétrica. ${ }^{24}$

Cabe recordar dos experiencias asiáticas. Tomemos como ejemplo de adaptación al caso de Japón, país que copió las mejores técnicas de Occidente, sin perder su carácter, lo que hizo precisamente con el fin de mantener su independencia. Contrariamente a Japón, que supo reconocer y corregir sus limitaciones en muchos aspectos, la actitud arrogante de China en el siglo pasado le valió muchas agresiones, de las cuales no fue objeto Japón, y con ello impidió que su desarrollo pudiera ser tal vez más rápido y menos dramático.

A lo largo de nuestra actividad en la esfera de las relaciones exteriores hemos insistido, entre otras cosas, en la conveniencia de ampliar nuestra capacidad de acción frente a Estados Unidos de América. Debemos actuar sin antagonizar innecesariamente a ese país, al que nos unen la geografía y la realidad de su poder. En pocas palabras, debemos buscar con seriedad una verdadera independencia y no limitarnos a agredirlo retóricamente, sin hacer algo efectivo que nos permita ser cada día menos dependientes.

También, de alguna manera, la preocupación en el mundo y en Estados Unidos de América, con quien ahora tenemos una relación más estrecha, es el medio ambiente. Ya que habrá de ajustarse nuestra industria a cánones más estrictos en esta materia. En la frontera norte actualmente hay miles de maquiladoras que se han establecido en años recientes, con 
gran visibilidad de sus desechos y, por supuesto, también han aumentado los grupos civiles de presión orientados a vigilar estos aspectos.

El tratado no ha modificado, en términos comparativos, nuestra relación con otros países, salvo, que se reconoció que Canadá, con o sin tratado, era un país importante para equilibrar nuestras relaciones. ${ }^{25}$ También hemos insistido desde hace tiempo en que Canadá es parte del "mundo Atlántico" al que estamos destinados a pertenecer, por lo que debemos acercarnos más, y tomar las medidas necesarias para llegar a ser puente entre Norteamérica y América Latina. Sin que por ello, por difícil que parezca, se olvide el objetivo de integración con ésta, ya que antes que todo somos latinoamericanos. Más que un grupo de países, somos una gran nación deshecha.

Con Canadá la relación fue siempre más fácil que con Estados Unidos de América, pues no es únicamente un socio comercial, dado que tenemos un sinnúmero de características en común. Entre las que destacan la vecindad con Estados Unidos de América, problema y ventaja común, las costas hacia el Atlántico y el Pacífico, la importancia de la inversión estadounidense y la dependencia comercial respecto de Estados Unidos de América. Es lógico, entonces que México y Canadá busquen incrementar sus contactos de cara a la relación que tienen con el vecino común.

La política exterior canadiense ha estado tradicionalmente marcada por su interés en contrarrestar la imponente fuerza de atracción y presión que ejerce Estados Unidos de América sobre ellos. ${ }^{26}$ De hecho, el primer acuerdo comercial que firmaron no hizo sino incrementar el temor canadiense por la pérdida de su identidad. Canadá empieza a reconocer que su viabilidad a corto plazo mejora con un acercamiento a sus vecinos del sur, y a largo plazo necesita buscar y crear nuevas opciones para equilibrar la presencia estadounidense.

La relación que Canadá mantiene con la Comunidad Británica de Naciones es cada vez menor en importancia, debido en parte a la creciente fortaleza de las relaciones intereuropeas. México debe entonces aprovechar esa coyuntura, lo que significa que la relación no debe limitarse al TLCAN. Sin duda a Canadá le convino la presencia de México en éste,

25 Véase Olloqui, José Juan de, México fuera de México, México, UNAM, 1980; y Rosas, Ma. Cristina, "Canadá y la geopolítica de América del Norte en los noventa", Comercio Exterior, México, núm. 2, febrero de 1994.

26 Véase Stuart, Reginald, "Antiamericanism in Canadian history", The American Review of Canadian Studies, Washington, núm. 2, verano de 1997. 
porque reafirma su identidad en las áreas que ellos están comparativamente más débiles.

Más aún ahora, ya que Quebec - la provincia que más difiere del resto de la Confederación Canadiense - ha tenido su segundo referendo, el cual perdieron los separatistas por escaso margen, pero que a nuestro juicio, como verdadero movimiento independentista que es, no va a aceptar la derrota como no sucede en una guerra de independencia. Una derrota no significa el fin de un movimiento y es de esperarse que éste siga insistiendo, además de que los regionalismos harán que quizá otras provincias busquen una aproximación a otros estados, como es el caso, por ejemplo de la Columbia Británica, que tiene más en común con los estados de Washington y Oregon que con las provincias marítimas. En fin, sería largo especular sobre todas las posibilidades que pueden suscitarse.

Desde hace tiempo hemos pensado en la posibilidad de que México y Canadá iniciaran un proyecto conjunto en el Caribe. Zona potencialmente explosiva que, si no se atiende, puede dar lugar a un eventual conflicto. Me explico, dentro del Commonwealth, los antiguos dominios, como por ejemplo Australia y Canadá, tienen de hecho asignadas zonas de acción. Así pues, Australia se ocupa de los países menos desarrollados de su zona, que pueden ser desde Papua-Nueva Guinea hasta incluso, el envío de fuerzas bajo la bandera de la ONU a Timor del Este hace poco tiempo.

Canadá, por su parte, tiene presencia en el Caribe angloparlante, que dicho sea de paso, cuenta con excelentes parlamentarios y representa dentro de la OEA el mayor número de votos. Nuestro país tiene profundas y antiguas ligas con Cuba, y goza de respeto por su personalidad.

Los países de la zona no mantienen una relación cada vez mayor sino por el contrario, cada vez disminuida con sus antiguas metrópolis. Su interés, aparte de Estados Unidos de América, se centra en África, Gran Bretaña, Francia, Holanda, la Comunidad Británica de Naciones y, en su momento, los Países No Alineados. Latinoamérica no mucho, aunque Venezuela sigue teniendo una fuerte presencia, con seis representaciones diplomáticas del más alto nivel: Institutos Culturales, etcétera, y nosotros sólo tenemos embajadas en el Caribe inglés, en Jamaica, Trinidad y Tobago y a veces un embajador itinerante.

Ni Estados Unidos de América ni Canadá han tenido la habilidad para llenar el vacío de las metrópolis. México podría participar más activamente en el área, y si se asocia en algún proyecto con Canadá, tampoco significaría amenaza para ninguna potencia, incluso podría verse con in- 
terés como una tercera y equilibrada posición. En un desayuno convocado hace unos tres o cuatro años por nuestra Cancillería con motivo de la visita a México del ministro de Asuntos Exteriores de Canadá, planteamos abiertamente esta posibilidad, que el propio primer ministro canadiense, a quien le interesó mucho la idea, y en una conversación que tuvo con nosotros después del desayuno, nos dijo que se ocuparía de esto con entusiasmo, lamentablemente, por los resultados, fue removido de su puesto.

"Ya entrados en gastos" y a propósito del Caribe, si a Belice lo consideramos más caribeño que centroamericano, es otra posibilidad que tenemos que manejar. Aunque las relaciones comerciales entre Canadá y México se han diversificado y aumentado, no tienen la intensidad que deberían. Aún perduran problemas como la triangulación comercial y el desconocimiento de los mercados. Desde que se anunció el TLCAN, ambos países hemos hecho verdaderos exámenes de conciencia, encontrando una cantidad cada vez mayor de puntos de coincidencia.

Los canadienses han descubierto que México representa un mercado importante, una fuente de productos complementarios y una tierra de inversión directa. Además, en el ámbito político se han ido estrechando las relaciones bilaterales. Existe amplio espacio de cooperación en áreas como la ecología, la educación, el petróleo, la vivienda, la agricultura, la pesca, el trabajo y el turismo. Canadá puede en parte convertirse en el factor de equilibrio en nuestras relaciones con Estados Unidos de América; además de que representa para México, la posibilidad de diversificar la inversión directa, una alternativa tecnológica y un amplio mercado.

Es importante dejar sentado que México debería acostumbrarse a hablar de una política hacia la comunidad noratlántica. La comunidad del Atlántico del Norte es tan válida como la Cuenca del Pacífico. Somos, como en la segunda, la orilla opuesta. Si bien no contamos con el potencial de Estados Unidos de América y Canadá, sí poseemos la posición geográfica, la población y los recursos necesarios, es más, al estar en el tratado sería ilógico no tener las mismas ligas que tienen Canadá y Estados Unidos de América - excepto en lo militar- con los países europeos. Nuestro ingreso per cápita tiende a parecerse al de algunos de los países europeos del Mediterráneo para desempeñar un papel protagónico. 


\section{LA BÚSQUEDA DE UN PUENTE CON EUROPA}

Intensificar la relación con Europa es nuestra más fácil alternativa. México despierta interés allí, porque la economía del país parece estar a punto de alcanzar una nueva magnitud. La dimensión de México como potencia emergente aún hoy es notable; baste pensar que nuestras tribulaciones han sacudido a todo el mundo.

Europa, acostumbrada a su esquema del Mercado Común Europeo, ahora Unión Europea, mantuvo gran interés por el cambio que se operaba en México. El cual paralelamente, iba a ser miembro del tratado y con quien tenía negociados interesantes esquemas, además de ser el primer país latinoamericano que ingresaba en la Organización para la Cooperación y el Desarrollo Económico (OCDE) y en el Banco Europeo de Reconstrucción y Desarrollo.

Lo anterior, aunado a la aparente o real modernización que se veía en muchos aspectos, fue sacudido con el levantamiento en Chiapas en 1994, y los asesinatos políticos posteriores. Sin embargo, México seguía siendo el país pivote que debía tenerse presente. Cabe decir que actualmente se negocian con la Unión Europea esquemas más complejos en nuestra relación. Seguramente será para bien.

El mercado mexicano con Estados Unidos de América alcanzó los $\$ 100$ billones en 1998, mientras que, el de Estados Unidos de América hacia la Unión Europea apenas se acercó a los \$4 billones en 1999. Europa es una posibilidad pero no una sustitución de la relación que tenemos con Estados Unidos de América, por razones de geografía. Es prudente recordar que un estratega como Bismarck, nunca desatendía su relación con Rusia, aunque actuaba intensamente para bien o para mal con otros países europeos.

En un momento dado, México hizo un intento de acercamiento al incipiente Mercosur, pero por diversas y obvias razones no hubo éxito. Nunca pretendió voltear las espaldas a América Latina ni al Caribe, pero simplemente no existía la posibilidad de integrarse a un bloque que diera los resultados que esperamos obtener del de Norteamérica.

\section{LA CONJUNCIÓN DE NORTEAMÉRICA CON AMÉRICA LATINA}

Nuestro ingreso al tratado fue visto en Latinoamérica con envidia y no muy buenos deseos. La prueba es que todos los países quisieron des- 
pués colocarse en posición de ingresar. También esto propició, hasta cierto punto y con el fin de equilibrarlo, que celebráramos otros tratados de Libre Comercio con países que no necesariamente nos van a favorecer, tales como con Chile, que entró en vigor el 1o. de enero de 1992; con Costa Rica, el 1o. de enero de 1995; con Bolivia, el 1o. de enero de 1995, y el del Grupo de los Tres, con Colombia y Venezuela, que entró en vigor el 1o. de enero de 1996.

Tampoco hay que descartar la posibilidad de iniciar o fortalecer nuestro comercio con África, la cual, dicho sea de paso, no se mencionó ni una sola vez en el Apartado de Soberanía del Plan Nacional de Desarrollo de 1994, ni siquiera para decir que no es prioridad. Hemos invertido bastante capital político, votando siempre por el anticolonialismo y antirracismo, en cambio no hemos sido capaces a veces de obtener su apoyo para la sede de algún campeonato deportivo. Cierto es que no tenemos la posición geográfica, composición racial o los antecedentes de Brasil respecto a ex-colonias portuguesas en África, aunque en nuestra multidiversidad algo podríamos decir.

No podemos tampoco seguir abriendo y cerrando embajadas, por la mala impresión que esto causa. En efecto, hemos cerrado entre otras, nuestra representación en Etiopía, Nigeria y Tanzania. Es decir, si se abrieron es porque se pensó que era una buena idea y no debieron cerrarse tan a la ligera, aún habiendo estrechez de recursos. El prestigio de un país cuesta mucho. Además es absurdo no intensificar nuestra relación, en muchos ámbitos, con África del Sur.

En un mundo globalizado, los cambios no se dan en el vacío o aislados. Por fuerza, se dan en el contexto mundial. Concretamente se dan en el contexto de la ubicación de México en el mundo. Se habla mucho de globalización y aún no existe una buena definición, aunque sí un consenso de lo que podemos entender por ella, de que es un proceso por el cual diversos Estados avanzan mediante la negociación hacia el establecimiento de un mecanismo conjunto de reglas y normas que gobiernen el quehacer de sus territorios, particularmente en lo económico, aunque esto no excluya aspectos más amplios. En efecto, la globalización abarca todo, cultura, aspectos políticos, etcétera.

Por lo anterior, me inclino por una definición más amplia, que sería la interrelación entre países en uno o varios aspectos de su actividad. Pienso que es muy claro que se trata de un fenómeno mundial y por me- 
dio de él intentamos obtener la diversificación que nos permita ejercer mejor todas nuestras opciones económicas y políticas.

El crecimiento, solo o aislado, no tiene sentido en un mundo globalizado. México tiene que redefinir su ubicación en el mundo, así pues, el crecimiento económico se debe ver reflejado hacia el exterior en su política. Esto significa redefinir nuestras relaciones con el exterior, en pocas palabras, cambiar nuestra política exterior. A mi juicio, se realizará sobre las siguientes bases y a la luz de dos conceptos básicos: independencia y diversificación.

Independencia: El logro de mayores márgenes de independencia en materia internacional ha sido, consciente o inconscientemente, uno de los objetivos centrales de nuestra política exterior. Sin embargo, los medios para alcanzar este objetivo y la manera de concebir el problema de la independencia han variado con el paso del tiempo.

La búsqueda de una posición independiente tuvo dos factores: la primera está relacionada con el desarrollo de una acción libre de ataduras en materia internacional. La segunda faceta toca raíces más profundas de nuestra posición con respecto a Estados Unidos de América y está vinculada a nuestro proyecto mismo de desarrollo, muy influido por los diagnósticos de la Comisión Económica de Naciones Unidas para América Latina (CEPAL).

Así, durante los decenios de 1960 y 1970, los países del Tercer Mundo, buscaron cambiar las reglas del juego económico internacional y propiciar de esta manera una mayor participación en las grandes corrientes del comercio y las finanzas. México no se mantuvo exento de estos fenómenos. Adoptamos primero una política sustitutiva de importaciones y luego una política exterior encaminada a cambiar el juego de la economía internacional convencidos de que con ellos, ganábamos mayores márgenes de independencia. Tanto en 1976, como en 1988 y 1994, sin embargo, la política exterior del país detuvo su impulso para poner más atención en el manejo de los problemas de la relación bilateral con Estados Unidos de América. ${ }^{27}$ Además, durante estos sexenios, uno de los objetivos prioritarios fue la diversificación de las relaciones económicas, pero al cabo de los mismos, las cifras seguían indicando un alto grado de concentración en nuestro vecino del norte. El problema para alcanzar una mayor independencia res-

27 Revisar las diferentes políticas de México y sus antecedentes en Sepúlveda, César, La política internacional de México en el decenio de los ochenta, México, FCE, 1994. 
pecto de nuestro vecino seguía sin resolverse y más bien parecíamos estar atados a una relación que habría que revisar cada seis años.

Diversificación: La segunda gran constante de nuestra política exterior ha sido la búsqueda de una mayor diversificación de las relaciones económicas y políticas. En esto se ha avanzado, pero todavía queda mucho por hacer. Se ha tratado, en realidad, de otra manera de concebir el logro de la independencia. Es curioso hacer notar que hasta hace poco México dejó de ver su ubicación geográfica como una fatalidad, comenzó a darse cuenta de la ventajosa situación geopolítica en la que está. Dicha extraordinaria multigeopoliticidad, sin embargo, no se ha aprovechado plenamente.

Nuestro país es uno de los más grandes de América Latina, el puente entre América del Norte y América Latina, el país latinoamericano con acceso a los dos océanos —el Atlántico y el Pacífico- así como el Caribe, nuestra tercer frontera. Por posición geográfica somos Norteamérica y por ende pertenecemos al Atlántico del Norte y al Pacífico Norte, las dos grandes cuencas en donde se toman las decisiones políticas y económicas que afectan el devenir internacional, a diferencia del Sur, donde tradicionalmente nunca trasciende nada. También somos centroamericanos. Muy pocos países en el mundo tienen las posibilidades geopolíticas de México. Este elemento debe convertirse en un asunto central en los cálculos de política económica y exterior. Si bien, nuestra política exterior no puede desentenderse de la vecindad con Estados Unidos de América, tampoco debe considerarla como su única determinante.

\section{LA OPCIÓN: POLÍTICA DE ABANICO}

La política exterior debe exigir el máximo aprovechamiento de nuestra privilegiada situación geopolítica. El México de hoy es un espacio abierto en donde confluyen las grandes corrientes de intercambio comercial, un puente entre distintas regiones del mundo, un marco dentro del cual conviven culturas tan diversas como la española, la indígena, la norteamericana, la oriental y la antillana. Estamos colocados en medio de las zonas de mayor interés en cuanto a transformaciones económicas se refiere y estamos en condiciones de aprovechar sus frutos. Así pues, la posición geopolítica de México es tan importante como nuestra historia, nuestra cultura, nuestros valores culturales, nuestra capacidad de defensa o nuestro grado de desarrollo económico, lo que nos otorga una extraordi- 
naria oportunidad para traducir esto en un exitoso programa diversificador. Nuestra política debería ser de "abanico", es decir, una política que sepa aprovechar todas nuestras dimensiones para edificar un programa más flexible y abierto.

Esto debe adquirir una formulación concreta en nuestra política exterior. Somos, entre otras cosas, un país norteamericano, atlántico, pacífico, centroamericano, caribeño, latinoamericano, hispanoparlante, plurirracial, una potencia cultural y emergente. Debemos pues, explotar la polivalencia de estas dimensiones.

Estas múltiples dimensiones de la política exterior ofrecen un abanico de opciones, a saber:

\section{La dimensión norteamericana}

Apenas hasta hace poco los mexicanos nos comenzamos a sentir parte de América del Norte. No nos consideraban ni nos considerábamos parte de esta América por nuestra condición de latinos, pero ahora, la frontera conceptual se está diluyendo por la naturaleza de nuestras relaciones económicas y los arreglos que hemos hecho para regularlas. La integración al mercado de América del Norte nos obliga a repensar nuestras relaciones con Canadá y Estados Unidos de América. Con respecto a Canadá, debemos seguir explorando las oportunidades que nos ofrece esa nación, que en el pasado estuvo totalmente ausente de nuestras prioridades y, con respecto a Estados Unidos de América, es necesario sacar una óptima ventaja económica y política. Creo que ha sonado la hora de madurar, de que nos decidamos a elaborar una política que vaya más allá de la reivindicación de posturas y mirar con aplomo hacia Canadá y Estados Unidos de América, sin que perdamos nuestra memoria histórica.

\section{La dimensión del Atlántico}

La dimensión atlántica de nuestra política exterior no sólo tiene que ver con nuestra posición geográfica, sino también con una rica herencia religiosa, cultural, política, científica y social de los países de Europa. Compartimos con ellos valores y aspiraciones comunes: una sociedad abierta, instituciones libres, economía de mercado.

Como se ha argumentado anteriormente, más allá de Estados Unidos de América y Canadá, existe un grupo de naciones industrializadas que por su peso, población, desarrollo y capacidad económica se presentan 
como una opción atractiva para balancear el excesivo peso de Estados Unidos de América sobre México. El objetivo a largo plazo sería que se nos considerara como miembros de pleno derecho en esta comunidad de países del Atlántico del Norte. Países que tienen el poder y el hábito de decidir. El inicio de la vigencia del Acuerdo de Libre Comercio con la Unión Europea el 1o. de julio del 2000 dio una nueva puerta a México hacia Europa. Si bien, la firma de este tratado no recibió la atención y dimensiones que el TLCAN suscitó en 1994, convierte a México en el único país que tiene tratados comerciales con dos de los tres bloques económicos en el mundo. Al convertirse en socio comercial de Norteamérica y Europa, México tiene que poner la vista a largo plazo en la tercer área más importante del orbe, que es el Pacífico Asiático y que encabeza Japón.

\section{La dimensión del Pacífico}

México cuenta con 7,000 kilómetros de litoral en el Océano Pacífico. Ésta es una realidad geográfica que también en los últimos años se ha convertido en una realidad económica y política. Ya se han dado los primeros pasos en la dirección correcta para insertar a México en una de las zonas más dinámicas del Planeta. La inclusión de México en la Conferencia Económica del Pacífico y como país miembro del Mecanismo de Cooperación Asia-Pacífico (APEC por sus siglas en inglés) nos hablan del éxito de estos esfuerzos. Sin embargo, nos falta mucho por hacer. Por supuesto que el foco de atención más jugoso del Pacífico es Japón, quien llega a ser en el siglo XX, una potencia cuyo peso en la definición de los grandes asuntos económicos internacionales será cada vez más importante. Si bien todavía nos falta mucho para desarrollar un intercambio económico con Japón, éste significa un contrapeso interesante respecto de Estados Unidos de América. Además de Japón en Asia, desde luego está China, con quien debemos explorar oportunidades de mayor intercambio.

\section{La dimensión centroamericana}

México también es un país centroamericano que durante muchos años ignoró ostensiblemente su frontera sur. Tuvo que venir la revolución nicaragüense y el despertar de las tensiones en el área para atrapar de manera definitiva nuestra atención sobre esta zona. Afortunadamente, el resentimiento dentro de los centroamericanos ha ido cediendo a una nueva era de paz, que debe convertirse en una de prosperidad. México debe eva- 
luar el peso que tiene el desarrollo de esta zona en su propia seguridad y prosperidad para convertirse en un país pivotal, en los esfuerzos de cooperación que saquen a esta región de la marginación y la pobreza en la que está sumida.

\section{La dimensión caribeña}

Nuestra tercera frontera, en el Caribe, ha sido también una zona que ha permanecido relativamente desatendida por nuestro país. Los países caribeños, anglófonos o francófonos en su mayoría, han estado alejados de nuestra actividad diplomática y económica. De cualquier forma, no vemos por qué esta región tenga que permanecer tan desatendida, cuando México puede aprovechar oportunidades de inversión y negocios, así como una coordinación diplomática más amplia en los foros multilaterales.

\section{La dimensión hispanoparlante}

México es el país de habla hispana más poblado del planeta. Asimismo, uno de cada tres hispanoparlantes en el mundo es mexicano o descendiente de ellos. Este hecho nos debería hacer reflexionar sobre nuestro peso en la comunidad hispanoparlante que se extiende desde Chicago y Nueva York hasta la Patagonia y nos une con Europa a través de España. ${ }^{28}$

\section{La dimensión plurirracial}

Somos una nación conformada por la unión y el choque de razas y culturas extraordinariamente vigorosas: europeos, indígenas, africanos y asiáticos han contribuido en mayor o menor medida con su gota de sangre para conformar el gran torrente que es la nación mexicana. Revisten especial interés las comunidades indígenas de otros países de América Latina y el mundo, que comparten los mismos retos que los nuestros para desarrollarse en la diversidad.

\section{La dimensión de potencia cultural}

México tiene 30 siglos de una civilización, más que de una cultura. Tiene 100 millones de habitantes y 20 millones de descendientes de mexicanos que viven en Estados Unidos de América. Esta dimensión políti-

28 Véase Carpizo, Jorge, "El peligro del voto de los mexicanos en el extranjero", Nexos, México, núm. 247, julio de 1998. Habría que resaltar cómo Carpizo lo ve como un peligro, y en cambio este texto lo considera una posibilidad. 
ca y cultural, debe ser explotada al máximo a través de nuestras letras, nuestro cine y nuestra televisión.

\section{La dimensión de potencia emergente}

Durante los años setenta esta dimensión, a la que le dábamos un enfoque tercermundista, parecía permear toda nuestra política exterior, causando serias distorsiones, de las que ya hemos hablado. Con el paso del tiempo nos hemos dado cuenta de que nuestra calidad de país en desarrollo no puede ser la única dimensión de nuestra política exterior; sin embargo, los asuntos que compartimos con las naciones en desarrollo siguen siendo muchos y mientras existan los agudos problemas del subdesarrollo seguiremos promoviendo una diplomacia que exija una mayor justicia internacional, aunque en la forma de un tercermundismo selectivo. México es una potencia media, lo que en realidad nos obliga a actuar en distintos mundos. Debido a esta posición, debemos evitar confrontaciones y fricciones innecesarias cuando así convenga a nuestros intereses.

\section{CONCLUSIÓN DE LA “DIPLOMACIA TOTAL”}

Por todo lo anterior, se debe seguir un nuevo tipo de diplomacia al que le doy el nombre de "Diplomacia total". Total por su necesidad de aprovechar todas las oportunidades del exterior en beneficio del país, total por su flexibilidad, porque no está enfocada a un solo grupo de países o de problemas, total por su capacidad de echar mano de todos sus recursos disponibles en la consecución de sus objetivos.

Esta idea de la "Diplomacia total" parte de la premisa de que la internacionalización de México no sólo es necesaria sino inevitable. México no ha permanecido ajeno a las transformaciones que ha sufrido el sistema internacional y, como la mayoría de los países del orbe, está buscando un reacomodo de su posición para aprovechar todas las oportunidades posibles.

Los objetivos para posicionar a México como país deben ser claramente definidos. De no hacerse así, se derrochan recursos y se cae en errores que en la diplomacia no son fáciles de enmendar, estos objetivos se deben elaborar bajo estos criterios: 


\section{Identificar claramente el interés nacional}

Diseñar nuestra política exterior significa identificar claramente el interés nacional. ${ }^{29}$ En ocasiones nos ha sucedido el absurdo de que por no tener de éste una idea clara, hemos actuado en contra de éste. Nada en política exterior se debe hacer en contra del interés nacional. Se debe recordar que los principios no constituyen en sí una política exterior.

\section{Identificar claramente la realidad internacional}

Existen tres posibilidades obvias de enfocar nuestra política exterior: a partir de lo que debe ser, de lo que quisiéramos que fuera y de lo que es. Respecto al deber ser, aunque pequemos de pragmatismo, nos parece necesario señalar que una política sustentada en abstracciones y buenos deseos, sirve de poco. Tampoco podemos engañarnos pensando que vivimos en un mundo que se adaptará fácilmente a nuestra voluntad. El voluntarismo a ultranza, sin una evaluación de nuestro poder, acabaría por erosionar nuestra postura internacional. ${ }^{30}$

Hay que tener siempre presente que para efecto de la política exterior es menester considerar y, más aún, ponderar, lo que debe ser, lo que uno quisiera que fuera y lo que es. Olvidar esto último nos llevaría a trabajar sobre supuestos imaginarios. Debemos diseñar nuestras acciones en función de lo que es. No nos desentendamos del deber ser o lo que quisiéramos que fuera, es decir, de los principios de nuestra política, ya que hacia allá debemos orientar nuestros objetivos a largo plazo, pero en principio estos objetivos deben estar encaminados a producir resultados y para esto deben basarse en la realidad.

\section{Evaluar los recursos. Ni somos una superpotencia ni somos el último de los países ${ }^{31}$}

El logro de los objetivos generales de política exterior requiere de políticas concretas diseñadas a partir de la realidad geopolítica y las circunstancias económicas, políticas y militares de la nación. La evaluación de

29 Véase Morgenthau, Hans J., "Otro gran debate: el interés nacional de los Estados Unidos”, en Vázquez, John A., Relaciones internacionales. El pensamiento de los clásicos, México, Limusa, 1994.

30 Véase González Aguayo, Leopoldo, "La geopolítica y el poder nacional”, Relaciones Internacionales, México, núm. 61, enero-marzo de 1994.

31 Véase tabla de posición de México, y fórmula de poder nacional en Cline, Ray, World Power Trends and U. S. Foreign Policy for the 1980s, Boulder, Westview, 1981. 
estos recursos debe ser objetiva y nos debe dar una idea clara de nuestra posición en el concierto de las naciones. Sería impensable pretender, por ejemplo, una política de gran potencia o actuar como si fuéramos uno de los últimos países subdesarrollados, como lo hemos hecho en el pasado.

Los objetivos en el exterior deben dar lugar al desarrollo de instrumentos ad-hoc. Estos no deben apartarse del peso específico que tiene México en la comunidad internacional y mucho menos alejarse de su condición de potencia media.

\section{Pensar a largo plazo y encadenar los objetivos con el mediano y el corto}

Para mejorar nuestra situación internacional, es necesario pensar en objetivos a largo plazo. Sólo así nuestras acciones adquirirán coherencia y se evitará improvisar posiciones de reunión en reunión y de conferencia en conferencia. A propósito de esto, queremos referir la siguiente anécdota: cuando el mariscal Hindenburg negociaba, al final de la Primera Guerra Mundial, con el recién instalado gobierno bolchevique y se negaba a entregar el territorio que posteriormente se convertiría en los países bálticos, los representantes alemanes, ante el impasse que se había producido por esta razón, preguntaron al mariscal el por qué de su insistencia en conservar estas áreas. Su respuesta fue categórica: las necesito para maniobrar mi ala izquierda en la siguiente guerra mundial. He aquí un ejemplo de planeación a largo plazo. En función de los fines que nos propongamos alcanzar a largo plazo, podremos definir objetivos de mediano y de corto plazo, esto debe ser por región, por país y por organismos, de manera que exista coherencia.

\section{Saber diversificar los objetivos}

Si bien es cierto que la política exterior debe tener continuidad, también debe diversificarse y, cuando sea necesario, modificar el orden de sus prioridades, según convenga al interés nacional. México debe saber manejar más de un objetivo, más de una opción.

\section{Mejorar la evaluación de las políticas}

Es indispensable que las políticas se enriquezcan con la planeación, la coordinación administrativa, el procesamiento de la información y la evaluación sistemática de las acciones emprendidas, a la luz de los objeti- 
vos que buscamos. No debemos conformarnos con obtener triunfos simbólicos, es necesario obtener triunfos reales.

Así, por ejemplo, el hecho de celebrar un tratado comercial no significa que se vaya a incrementar el comercio en nuestro beneficio. Es necesario el seguimiento para lograr que el contenido del tratado tenga vigencia: no basta con informar que no se ha cumplido, sino emprender las acciones para que se cumpla. De la misma manera, el que nuestras embajadas remitan informes políticos o adviertan de actividades comerciales, tiene poco sentido si no hay un procesamiento de la información para hacerla útil. En estas circunstancias, no es de extrañar la falta de aprovechamiento de nuestras potencialidades. Dudamos que exista un país con mejores sistemas de información y distribución de ésta que Estados Unidos de América. Sin embargo, no han podido optimizarlas.

Al definir los objetivos, no hay que confundirlos con los principios. Aunque como he dicho, principios y objetivos no tienen por qué chocar necesariamente unos con otros. Definidos los objetivos, se identifican los recursos y se define la estrategia para resolverlos, evaluando las políticas en forma periódica. Este ejercicio debe tener dos fases: global y por áreas.

\section{Blancos de oportunidad}

No olvidemos la posibilidad de un "blanco de oportunidad", esto es aprovechar las opciones que aparecen en el horizonte y que no estaban originalmente consideradas. La omisión en el quehacer internacional es una falta grave para los intereses del país.

\section{Evaluar y avanzar}

No basta con planear los objetivos a lograr con cada país o cada región, también es necesario ir avanzando persistentemente hacia las metas trazadas. De la misma manera en que se revisan los planes nacionales de desarrollo, se deberían evaluar los planes de política exterior. Cabe agregar que a veces se confunde la actividad con la efectividad. Existe en México la tendencia a engañarnos a nosotros mismos "haciendo como que hacemos". Esto es ridículo y no se justifica ya en un país de las dimensiones de México. Si tan sólo los mexicanos nos viéramos como nos ven en el extranjero por este y otro tipo de errores. 
9. Hay que usar todos los recursos: iniciativa privada, cultura (en la que somos una gran potencia) deporte, $T$. V., etcétera

El objetivo de la "Diplomacia total” se resume en cuatro palabras: la grandeza de México. ¿Por qué no hablamos de una misión de liderazgo? Porque no se es líder por decirlo ni se deja de serlo por negarlo.

Definimos esta grandeza como:

- Un país justo en lo interno, ya que sin justicia social la libertad y el progreso carecerían de sentido

- Un país del que los mexicanos y sus descendientes se puedan sentir orgullosos.

- Un país próspero en el que los mexicanos tengan satisfechas sus necesidades básicas y cuenten con amplias posibilidades de desarrollo personal y social.

- Un país respetado por su apego a los mejores principios, por el éxito de su política exterior y por su estatura en la comunidad internacional.

- Un país capaz de defender su soberanía y su integridad.

Para posicionar a México como país hay que redefinir las relaciones de México con el exterior para que reflejen su nueva realidad y que ésta sea congruente con su nueva situación y ubicación en el contexto mundial. Asimismo, se requiere que esta nueva relación de México con el resto del mundo apoye y sirva para dar impulso a la nueva realidad mexicana.

Para concluir, sólo los resultados cuentan, sólo el éxito se respeta y nada debe de estar sobre el interés nacional. Un razonable e ilustrado nacionalismo entendido como afirmación de lo nuestro y no negación de lo ajeno, siempre será bien visto. ${ }^{32}$

Por todo esto consideramos que México está condenado a la grandeza. Condenado a la grandeza y no destinado, porque la nación mexicana no buscó esta sentencia sino que le fue impuesta por el destino. El destino al que esta condenado México, es indudablemente el de la grandeza. 